УДК 615.32:547.9+543.544

\title{
КОЛИЧЕСТВЕННОЕ ОПРЕДЕЛЕНИЕ САПОНИНОВ В ПРЕПАРАТАХ АРАЛИИ МАНЬЧЖУРСКОЙ
}

\author{
(C) В.А. Куркин , Т.К. Рязанова, Л.В. Зулькарняева \\ Самарский государственный медицинский университет, ул. Чапаевская, 89, \\ Самара, 443099 (Россия), e-mail: Kurkinvladimir@yandex.ru
}

Разработана методика количественного определения содержания сапонинов в препаратах (настойке и сиропах) на основе корней аралии маньчжурской (Aralia elata (Miq.) Seem., синоним: A. mandshurica Rupr. et Maxim.) методом прямой спектрофотометрии после реакции с концентрированной серной кислотой (аналитическая длина волны 510 нм для настоек, 525 нм для сиропов). Количественное определение сапонинов в сиропах проводили после предварительного гидролиза с использованием $20 \%$ раствора серной кислоты в течение 2 ч. Содержание сапонинов в образцах настоек варьировало от $1,51 \pm 0,05$ до $1,72 \pm 0,06 \%$ в пересчете на аммонийную соль аралозидов А, В, С с усредненной молекулярной массой, в сиропах - от $0,131 \pm 0,003 \%$ до 0,145 $\pm 0,004 \%$ в пересчете на олеаноловую кислоту, что в переводе на аммонийную соль аралозидов А, В и С с усредненной молекулярной массой соответствует $0,287-0,318 \%$. Определено, что ошибка единичного определения содержания сапонинов в настойке из корней аралии маньчжурской с доверительной вероятностью $95 \%$ составляет $\pm 3,44 \%$, в сиропе из «Сапарала» - $\pm 2,62 \%$, а в сиропе из настойки $- \pm 3,17 \%$.

Ключевые слова: аралия маньчжурская, Aralia elata (Miq.) Seem., A. mandshurica Rupr. et Maxim., сапонины, аралозиды, олеаноловая кислота, «Сапарал», сироп, настойка, стандартизация, спектрофотометрия.

\section{Введение}

Корни аралии маньчжурской (Aralia elata (Miq.) Seem., синоним: A. mandshurica Rupr. et Maxim.) широко используются в официнальной медицине в качестве источника лекарственных средств с общетонизирующей, адаптогенной активностью [1]. Согласно литературным данным, считается, что фармакологическое действие корней аралии обусловлено сапонинами (аралозидами) - гликозидами олеаноловой кислоты [1] (рис. 1).

На данный момент препараты на основе корней аралии маньчжурской на фармацевтическом рынке Российской Федерации немногочисленны и представлены настойками четырех производителей (ОАО «Дальхимфарм», ОАО «Кировская фармацевтическая фабрика», ОАО «Тверская фармфабрика», ОАО «Владивостокская фармфабрика»). Корни аралии маньчжурской также входят в состав противодиабетического растительного сбора «Арфазетин» [2]. Ранее существовал препарат «Сапарал» (таблетки 0,05 г), содержащий аммонийные соли аралозидов [3]. Как известно, лекарственная форма оказывает определенное психологическое воздействие на пациентов, которое может повлиять на эффективность лекарственной терапии. Наиболее значима проблема корригирования при производстве жидких пероральных лекарственных

Куркин Владимир Александрович - заведующий кафедрой фармакогнозии с ботаникой и основами фитотерапии, профессор, доктор фармацевтических наук, тел. (846) 260-33-59, e-mail: Kurkinvladimir@yandex.ru

Рязанова Татьяна Константиновна - заведующий лабораторией санитарно-химических методов исследования НИИ гигиены и экологии человека, кандидат фармацевтических наук, тел. (846) 260-33-59, e-mail: ryazantatyana@mail.ru

Зулькарняева Ляйсян Ваилевна - студентка, e-mail: zulkarnjaeva-lesja@rambler.ru форм, причем одним из важных факторов являются удобство применения [4]. Лекарственной формой, имеющей приятные органолептические свойства и позволяющей корригировать неприятные вкусовые ощущения, являются сиропы. Согласно результатам анализа ассортимента адаптогенов на фармацевтическом рынке РФ на данный момент среди лекарственных средств отсутствуют сиропы на основе растительных адаптогенов [5].

\footnotetext{
* Автор, с которым следует вести переписку.
} 


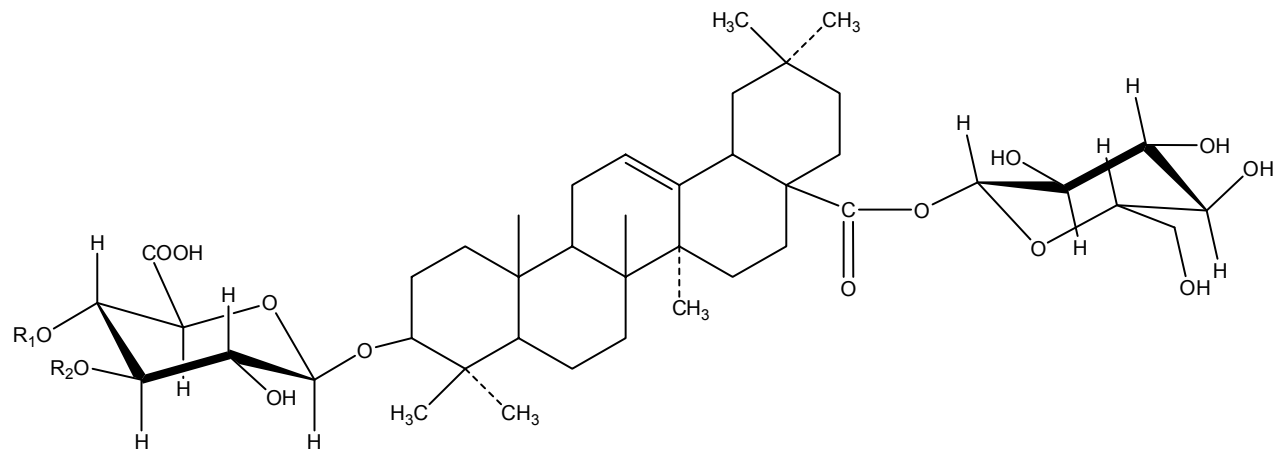

\begin{tabular}{c|c|c}
\hline Гликозид & $\mathrm{R}_{1}$ & $\mathrm{R}_{2}$ \\
\hline Аралозид $A$ & $\alpha$-L-арабинофуранозил & $\mathrm{H}$ \\
Аралозид $B$ & $\alpha$-L-арабинофуранозил & $\alpha$-L-арабинофуранозил \\
Аралозид $C$ & $\beta$-D-галактопиранозил & $\beta$-D-ксилофуранозил \\
\hline
\end{tabular}

Рис. 1. Структурные формулы аралозидов

Кроме этого, имеются определенные трудности со стандартизацией сырья и препаратов аралии маньчжурской. Методика количественного определения суммы сапонинов в действующей фармакопейной статье на корни аралии маньчжурской многостадийна и трудоемка, возможны значительные потери действующих соединений на различных этапах процесса [6]. Известные методики анализа препаратов аралии основаны на методике анализа сырья. В литературных источниках описана методика количественного определения сапонинов после предварительного гидролиза в пересчете на олеаноловую кислоту методом ультрафиолетовой спектрофотометрии при аналитической длине волны 310 нм [7]. На наш взгляд, в используемой для анализа области спектра возможно внесение вклада других природных соединений. В связи с этим была выбрана длина волны 510 нм (для аралозидов) и 525 нм (для олеаноловой кислоты), характерными максимумами в длинноволновой области для этих соединений после обработки концентрированной серной кислотой.

Цель данного исследования - разработка современных методов оценки количественного содержания сапонинов (аралозидов) в препаратах аралии маньчжурской: настойке и перспективной лекарственной форме - сиропе. Нами исследовались сиропы, полученные из настойки аралии и из субстанции «Сапарал» (сумма аммонийных солей аралозидов с содержанием сапонинов не менее $80 \%$ ).

\section{Экспериментальная часть}

Объектами исследования являлись промышленные образцы «Аралии настойка» (производства ОАО «Дальхимфарм» и ОАО «Тверская фармацевтическая фабрика»), образцы субстанции «Сапарал» с содержанием сапонинов 85,0\%, рабочий образец аралозида А (степень чистоты 97,0\%) и рабочие образцы сиропов, полученных из настойки и «Сапарала» (корригент - сорбит). Сиропы получали на основании вкусового сиропа, полученного по стандартной технологии [8], в который настойку или «Сапарал» добавляли таким образом, чтобы содержание действующих веществ в столовой ложке составляло 50 мг (разовая доза).

В исследовании использовали спектрофотометрический метод. Регистрацию спектров проводили с помощью спектрофотометров «Specord 40» (Analytik Jena) и СФ-2000.

С целью разработки методики количественного определения аралозидов изучены спектры поглощения извлечения из корней аралии маньчжурской и «Сапарала» после взаимодействия с концентрированной серной кислотой (рис. 2).

В качестве аналитической нами была выбрана длина волны 510 нм. В качестве стандарта использовали «Сапарал», который, на наш взгляд, соответствует аммонийной соли аралозидов А, В, С с усредненной молекулярной массой, в пересчете на которую проводится количественное определение в фармакопейной статье [6].

Для анализа настоек 2,0 мл препарата помещали в мерную колбу вместимостью 25 мл, доводили 95\% этиловым спиртом до метки (раствор А). 10,0 мл полученного раствора помещали в мерную колбу вместимостью 25 мл, доводили 95\% этиловым спиртом до метки (раствор В). К 1,0 мл полученного раствора добавляли 4,0 мл концентрированной серной кислоты, нагревали при перемешивании на кипящей водя- 
ной бане 15 мин. После охлаждения измеряли оптическую плотность испытуемого раствора на спектрофотометре при длине волны 510 нм в кювете с толщиной слоя 10 мм. В качестве раствора сравнения использовали приготовленный следующим образом раствор: к 1,0 мл 95\% этилового спирта добавляли 4,0 мл концентрированной серной кислоты, нагревали на кипящей водяной бане при перемешивании 15 мин, охлаждали до комнатной температуры.

Приготовление раствора рабочего стандартного образияа «Сапарала». 0,05 г «Сапарала» (точная навеска) помещают в мерную колбу вместимостью 100 мл. Растворяют в 20 мл воды очищенной и доводят водой очищенной до метки. К 1,0 мл полученного раствора добавляют 4,0 мл концентрированной серной кислоты, нагревают на кипящей водяной бане при перемешивании в течение 15 мин.

После охлаждения измеряют оптическую плотность испытуемого раствора на спектрофотометре при длине волны 510 нм в кювете с толщиной слоя 10 мм на фоне раствора сравнения.

Содержание суммы сапонинов (X) в пересчете на аммонийную соль аралозидов А, B, С с усредненной молекулярной массой в процентах вычисляют по формуле

$$
X=\frac{D \cdot m_{0} \cdot X_{a r} \cdot 25 \cdot 25 \cdot 5 \cdot 1 \cdot 100}{D_{0} \cdot 2 \cdot 10 \cdot 1 \cdot 50 \cdot 5}=\frac{D \cdot m_{0} \cdot X_{a r} \cdot 62,5}{D_{0} \cdot m},
$$

где $D$ - оптическая плотность испытуемого раствора; $D_{0}$ - оптическая плотность раствора РСО «Сапарала»; $m_{0}$ - навеска «Сапарала», г; $X_{a r}$ - степень чистоты «Сапарала», \%;

При отсутствии рабочего образца «Сапарала» возможно использование удельного показателя поглощения - 56,0:

$$
X=\frac{D \cdot 25 \cdot 25 \cdot 5}{2 \cdot 10 \cdot 1 \cdot 56}=\frac{D \cdot 62,5}{m \cdot 112}
$$

где $D$ - оптическая плотность испытуемого раствора; 56 - значение удельного показателя поглощения для «Сапарала» (аммонийной соли аралозидов А, В и С с усредненной молекулярной массой) после взаимодействия с концентрированной серной кислотой при аналитической длине волны 510 нм.

Содержание суммы сапонинов в проанализированных образцах настоек аралии маньчжурской варьировало от $1,51 \pm 0,05$ до $1,72 \pm 0,06 \%$.

Результаты статистической обработки проведенных опытов показывают, что ошибка единичного определения суммы сапонинов в корнях аралии маньчжурской с доверительной вероятностью 95\% составляет $\pm 3,44 \%$.

Метрологические характеристики метода количественного определения суммы сапонинов в настойке аралии маньчжурской представлены в таблице 1.

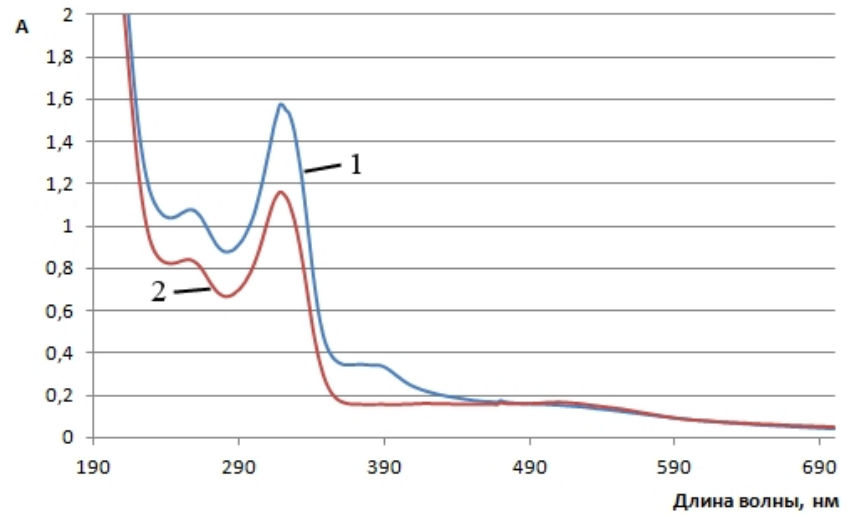

Рис. 2. Спектры поглощения извлечения из корней аралии маньчжурской (1), «Сапарала» (2) после взаимодействия с концентрированной серной кислотой

Таблица 1. Метрологические характеристики методики количественного определения сапонинов в настойке аралии маньчжурской (производства ОАО «Дальхимфарм»)

\begin{tabular}{c|c|c|c|c|c|c|c}
\hline $\mathrm{n}$ & $\mathrm{f}$ & $\bar{X}$ & $\mathrm{~S}$ & $\mathrm{P}, \%$ & $\mathrm{t}(\mathrm{P}, \mathrm{f})$ & $\Delta \mathrm{X}$ & $\mathrm{E}, \%$ \\
\hline 6 & 5 & 1,60 & 0,05198 & 95 & 2,57 & $\pm 0,055$ & $\pm 3,44$ \\
\hline
\end{tabular}


Таблица 2. Сравнительная характеристика экстракционной способности различных растворителей (с использованием сиропа из «Сапарала»)

\begin{tabular}{l|c}
\hline \multicolumn{1}{c|}{ Растворитель } & $\begin{array}{c}\text { Степень извлечения } \\
\text { сапонинов, \% }\end{array}$ \\
\hline Хлороформ & $46 \pm 2$ \\
Хлороформ - этиловый & $97 \pm 2$ \\
$\begin{array}{l}\text { спирт 95\% (9 : } 1) \\
\text { Хлороформ - этиловый } \\
\text { спирт 95\% (4: } 1)\end{array}$ & $99 \pm 2$ \\
\hline
\end{tabular}

В связи с мешающим влиянием корригента (сорбита) на результаты количественного определения сапонинов в сиропах из настойки аралии и «Сапарала» мы проводили предварительный гидролиз аралозидов до агликона (олеаноловой кислоты). Гидролиз проводили с использованием 20\% раствора серной кислоты в течение 2 ч. Для извлечения из реакционной смеси агликона использовали жидкостьжидкостную экстракцию. В таблице 2 представлена сравнительная характеристика извлекающей способности смесей растворителей. Исследование экстрак-

ционной способности растворителей проводили с использованием сиропа из «Сапарала», для которого было известно содержащееся в нем количество сапонинов.

Таким образом, оптимальной извлекающей способностью обладает смесь хлороформа и 95\% этилового спирта в соотношении $4: 1$.

Количественное определение сапонинов в сиропе, как и в настойке, проводили прямым спектрофотометрическим методом после взаимодействия с концентрированной серной кислотой. Оптическую плотность измеряли при аналитической длине волны 525 нм, которая соответствует длинноволновому максимуму поглощения олеаноловой кислоты после реакции с серной кислотой (рис. 3).

\section{Методика количественного определения сапонинов в сиропах аралии}

5,0 г сиропа (точная навеска) помещают в коническую колбу вместимостью 100 мл, добавляют 7,5 мл $20 \%$ раствора серной кислоты и нагревали на кипящей водяной бане с обратным холодильником в течение 2 ч. Полученный раствор охлаждают, помещают в делительную воронку и экстрагируют образовавшийся агликон (олеаноловую кислоту) смесью хлороформа и 95\% этилового спирта в соотношении $4: 1$. Экстракцию проводили три раза, каждый раз сливая нижний слой в коническую колбу. Полученный экстракт промывают водой очищенной. После отделения хлороформное извлечение упаривают досуха в фарфоровой чашке на кипящей водяной бане. Остаток растворяют в 95\% этиловом спирте и количественно переносят в мерную колбу вместимостью 25 мл. К 1,0 мл полученного раствора добавляют 4,0 мл концентрированной серной кислоты и нагревают на кипящей водяной бане в течение 15 мин.

После охлаждения измеряют оптическую плотность испытуемого раствора на спектрофотометре при длине волны 525 нм в кювете с толщиной слоя 10 мм. В качестве раствора сравнения используют приготовленный следующим образом раствор: к 1,0 мл 95\% этилового спирта добавляют 4,0 мл концентрированной серной кислоты, нагревают на кипящей водяной бане при перемешивании 15 мин, охлаждают до комнатной температуры.

Параллельно готовят раствор стандартного образца олеаноловой кислоты. 0,02 г олеаноловой кислоты (точная навеска) помещают в мерную колбу вместимостью 100 мл. Растворяют в 95\% этиловом спирте при нагревании. К 1,0 мл полученного раствора добавляют 4,0 мл концентрированной серной кислоты, нагревают на кипящей водяной бане при перемешивании в течение 15 мин.

Содержание суммы сапонинов в процентах $(\mathrm{X})$ в пересчете на олеаноловую кислоту рассчитывают по формуле

$$
X=\frac{D \cdot m_{0} \cdot 25 \cdot 5 \cdot 1 \cdot 100}{D_{0} \cdot m \cdot 1 \cdot 100 \cdot 5}=\frac{D \cdot m_{0} \cdot 25}{D_{0} \cdot m},
$$

где $\mathrm{D}$ - оптическая плотность испытуемого раствора; $\mathrm{D}_{0}$ - оптическая плотность раствора СО олеаноловой кислоты; m - масса навески сиропа, г; $\mathrm{m}_{0}$ - навеска олеаноловой кислоты, г.

Содержание сапонинов в сиропе в пересчете на олеаноловую кислоту варьировало от $0,131 \pm 0,003$ до $0,145 \pm 0,004 \%$. С учетом средней молекулярной массы сапонинов (1000 г/моль) содержание сапонинов в сиропах составляло 0,287-0,318\% в пересчете на аммонийную соль аралозидов А, В и С с усредненной молекулярной массой.

Результаты статистической обработки проведенных опытов показывают, что ошибка единичного определения суммы сапонинов в сиропе из сапралаа с доверительной вероятностью 95\% составляет $\pm 2,62 \%$, в сиропе из настойки - $\pm 3,17 \%$. Метрологические характеристики метода количественного определения суммы сапонинов в сиропе аралии маньчжурской представлены в таблице 3. 
Рис. 3. Спектр поглощения олеаноловой кислоты (1) и сиропа аралии маньчжурской (2) после взаимодействия с концентрированной серной кислотой

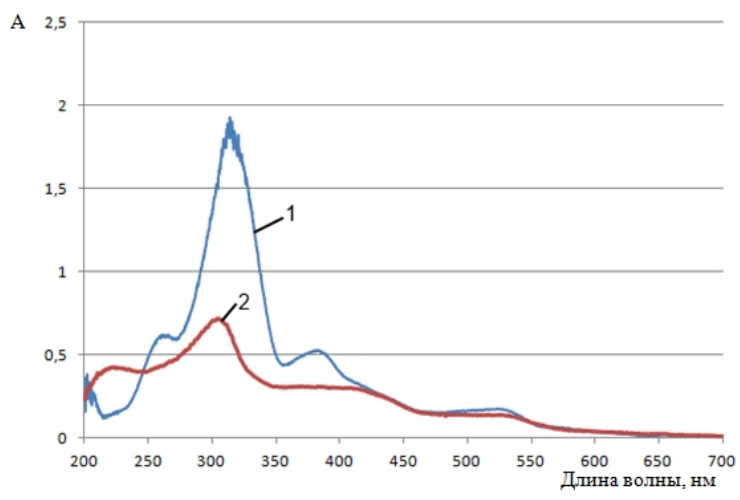

Таблица 3. Метрологические характеристики методики количественного определения сапонинов в сиропах аралии маньчжурской

\begin{tabular}{l|c|c|c|c|c|c|c|c}
\hline \multicolumn{1}{c|}{ Объект } & $n$ & $f$ & $\bar{X}$ & $S$ & $P, \%$ & $t(P, f)$ & $\Delta X$ & $E, \%$ \\
\hline Сироп из «Сапарала» & 7 & 6 & 0,141 & 0,004 & 95 & 2,446 & $\pm 0,004$ & $\pm 2,62$ \\
Сироп из настойки & 7 & 6 & 0,144 & 0,0049 & 95 & 2,446 & $\pm 0,005$ & $\pm 3,17$ \\
\hline
\end{tabular}

\section{Выводы}

Таким образом, в ходе исследования были разработаны методика количественного определения суммы сапонинов в настойке и сиропах аралии маньчжурской методом прямой спектрофотометрии после взаимодействия с концентрированной серной кислотой. Все полученные результаты были статистически

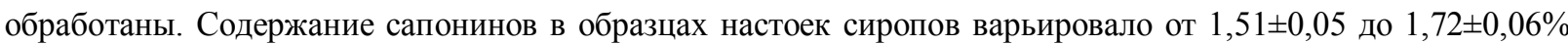
в пересчете на аммонийную соль аралозида с усредненной молекулярной массой, в сиропах от $0,131 \pm 0,003$ до $0,145 \pm 0,004 \%$ в пересчете на олеаноловую кислоту, что в переводе на аммонийную соль аралозидов А, В и С с усредненной молекулярной массой соответствует 0,287-0,318\%.

\section{Список литературы}

1. Куркин В.А. Фармакогнозия: учебник для студентов фармацевтических вузов (факультетов.). 2-е изд., перераб. и доп. Самара, 2007. 1239 с.

2. Государственный реестр лекарственных средств [Электронный ресурс]. Электрон. дан. 2015. Режим доступа: http://grls.rosminzdrav.ru/grls.aspx.

3. Минина С.А., Каухова И.Е. Химия и технология фитопрепаратов: учебное пособие. М., 2004. 560 с.

4. Чуешов В.И., Чернов М.Ю., Хохлова Л.М. и др. Промышленная технология лекарств: учебник для студентов высших учебных заведений. В 2 т. Т. 2. Харьков, 1999. 704 с.

5. Куркин В.А., Петрухина И.К., Акушская А.С. Исследование номенклатуры адаптогенных лекарственных препаратов, представленных на фармацевтическом рынке Российской Федерации // Фундаментальные исследования. 2014. №8, Ч. 4. С. 898-902.

6. Государственная фармакопея СССР: Вып. 2. Общие методы анализа. Лекарственное растительное сырье. МЗ СССР. 11-е изд., доп. М., 1990. 400 с.

7. Писарев Д.И., Н.А. Мартынова Н.Н. Нетребенко и др. Сапонины и их определение в корневищах аралии маньчжурской в условиях Белгородской области // Химия растительного сырья. 2009. №4. С. 197-198.

8. ОФС.1.4.1.0012.15 «Сиропы». Государственная фармакопея Российской Федерации: Т. 2. МЗ РФ. 13-е изд. M., 2015. 1004 c.

Поступило в редакичию 26 мая 2016 г. 
Kurkin V.A. ${ }^{*}$, Ryazanova T.K., Zulkarnyaeva L.V. QUANTITATIVE DETERMINATION OF SAPONINS IN THE DRUGS OF ARALIA ELATA

Samara State Medical University, Chapaevskaia st., 89, Samara, 443099 (Russia), e-mail: Kurkinvladimir@yandex.ru

The method of the quantitative determination of the content of total saponins in the herbal drugs (tincture and syrup) of Aralia elata (Miq.) Seem. (synonym: Aralia mandshurica Rupr. et Maxim.) was developed by means of the direct spectrophotometry following reaction with concentrated sulfuric acid (analytical wavelength $-510 \mathrm{~nm}$ for tincture and $525 \mathrm{~nm}$ for syrups). The quantitative determination of the content of total saponins in syrups was conducted following preliminary hydrolysis in the presence of $20 \%$ sulfuric acid during two hours. The content of total saponins in the tincture varies from $1.51 \pm 0.05 \%$ to $1.72 \pm 0.06 \%$ calculated on ammonium salt of aralosides A, B, C with average molecular weight, in syrups from $0.131 \pm 0.003 \%$ to $0.145 \pm 0.004 \%$ calculated on oleanolic acid $(0.287-0.318 \%$ calculated on ammonium salt of aralosides $\mathrm{A}, \mathrm{B}, \mathrm{C}$ with average molecular weight). It was determined that the error of a single definition of the contents of total saponins in the tincture from the roots of Aralia mandshurica with confidence probability of $95 \%$ is $\pm 3.14 \%$, in syrup from "Saparal" $\pm 2.62 \%$, in syrup from tincture $\pm 3.17 \%$.

Keywords: Aralia elata (Miq.) Seem., Aralia mandshurica Rupr. et Maxim., saponins, aralosides, oleanolic acid, saparal, tincture, syrup, standardization, spectrophotometry.

\section{References}

1. Kurkin V.A. Farmakognoziia. [Pharmacognosy]. Samara, 2007, 1239 p. (in Russ.).

2. Gosudarstvennyi reestr lekarstvennykh sredstv. [State Register of Medicines]. 2015. [Electronic resource]. URL: http://grls.rosminzdrav.ru/grls.aspx. (in Russ.).

3. Minina S.A., Kaukhova I.E. Khimiia i tekhnologiia fitopreparatov. [Chemistry and technology of phytopreparations]. Moscow, 2004, 560 p. (in Russ.).

4. Chueshov V.I., Chernov M.Iu., Khokhlova L.M. et al. Promyshlennaia tekhnologiia lekarstv. [Industrial technology of medicines]. Kharkiv, 1999. vol. 2, 704 p. (in Russ.).

5. Kurkin V.A., Petrukhina I.K., Akushskaia A.S. Fundamental'nye issledovaniia, 2014, no. 8, part. 4, pp. 898-902. (in Russ.).

6. Gosudarstvennaia farmakopeia SSSR: Vyp. 2. Obshchie metody analiza. Lekarstvennoe rastitel'noe syr'e. [State Pharmacopoeia of the USSR: Vol. 2. General methods of analysis. Medicinal plant raw materials]. 11 ed. Moscow, 1990, 400 p. (in Russ.).

7. Pisarev D.I., N.A. Martynova N.N. Netrebenko et al. Khimiia rastitel'nogo syr'ia, 2009, no. 4, pp. 197-198. (in Russ.).

8. Gosudarstvennaia farmakopeia Rossiiskoi Federatsii: T. 2. OFS.1.4.1.0012.15 «Siropy». [ State Pharmacopoeia of the Russian Federation: T. 2. OFS.1.4.1.0012.15 "Syrups"]. 13 ed. Moscow, 2015, 1004 p. (in Russ.).

Received May 26, 2016

Revised March 2, 2017

\footnotetext{
* Corresponding author.
} 